\title{
Estimativa do intervalo pós-morte em um canino (Canis lupus familiaris Linnaeus 1758) pela entomologia forense em Cabedelo-PB, Brasil: relato de caso
}

\author{
[Estimate of postmortem interval through forensic entomology in a canine (Canis lupus familiaris Linnaeus 1758) in \\ Cabedelo-PB, Brazil: case report] \\ G. Martins ${ }^{1}$, W.E. dos Santos $^{2}$, A.J. Creão-Duarte ${ }^{2}$, L.B.G. da Silva ${ }^{3}$, A.A.F. Oliveira ${ }^{3 *}$ \\ ${ }^{1}$ Aluno de pós-graduação - Universidade Federal Rural de Pernambuco - UFRPE -Recife, PE \\ ${ }^{2}$ Universidade Federal da Paraíba - João Pessoa, PB \\ ${ }^{3}$ Universidade Federal Rural de Pernambuco - UFRPE - Recife, PE
}

\begin{abstract}
RESUMO
O intervalo pós-morte (IPM) é um instrumento importante de diagnóstico relacionado à prática forense. O uso de insetos tem sido relatado como um modo eficiente para estimá-lo, quando o cadáver encontra-se em estágio avançado de decomposição. Objetivou-se com este trabalho estimar o IPM com base em evidências entomológicas em um canino. Foram coletadas larvas de moscas no cadáver e encaminhadas ao laboratório de entomologia, onde foram criadas e eclodiram adultos da espécie Chrysomya albiceps (Wiedemann, 1819). Somando-se os dados abióticos de temperatura e umidade relativa do local de coleta e do local de criação, estimou-se um IPM mínimo de 3,34 dias do momento da postura dos ovos pelas moscas até a coleta das larvas. Com base nos resultados obtidos, conclui-se que a entomologia forense, como ferramenta para estimativa do IPM, mostrou-se eficaz e determinante na elucidação do caso em questão.
\end{abstract}

Palavras-chave: mosca varejeira, Calliphoridae, Canidae, medicina veterinária legal

\begin{abstract}
The postmortem interval (PMI) is an important tool for diagnosis related to the forensic practice. The use of insects has proved to be an efficient diagnosis tool when the cadaver is in advanced decomposition stage. The objective of this work was to estimate PMI based on entomological evidence in a canine. Fly larvae was collected from the cadaver and forwarded to the Entomology laboratory. The fly larvae were reared and hatched adults of Chrysomya albiceps (Wiedemann 1819). With these insects and the abiotic data of temperature and relative humidity, from the places of collection and rearing larvae, a minimum PMI of 3.34 days from the laying of eggs by the flies until the time that we collected the larvae was obtained. The results show that Forensic Entomology as tool to estimate PMI is decisive and effective in the elucidation of the case.
\end{abstract}

Keywords: blow flies, Canidae, Calliphoridae, Forensic Veterinary Medicine

\section{INTRODUÇÃO}

Os insetos são atraídos para um cadáver imediatamente após a morte, geralmente em minutos, em decorrência dos gases e odores liberados (Smith, 1986). Entre esses, as moscas (Ordem Diptera), tipicamente, são os primeiros colonizadores (Fisher et al., 1998).
Além da relevância ecológica na decomposição, os insetos colonizadores de cadáveres podem se tornar importantes instrumentos em investigações criminais, de modo particular naquelas envolvendo morte de caráter violento, por possibilitarem estimativa do intervalo pósmorte (IPM) e, ainda, permitirem estudos moleculares baseados na análise de DNA.

Recebido em 24 de outubro de 2012

Aceito em 13 de março de 2013

*Autor para correspondência (corresponding author)

E-mail: andreaafo@hotmail.com 
Entre os insetos presentes no cadáver, os necrófagos representam papel fundamental para tal finalidade. Pelo fato de se reproduzirem e completarem seu ciclo de vida exclusivamente nesse ambiente, a determinação da idade desses insetos consiste na base para a estimativa do IPM pelo método entomológico (Catts e Goff, 1992).

A estimativa de IPM foi conduzida com utilização de evidência entomológica na Península Ibérica, quando se estabeleceu o ano da morte em cadáver humano, após o exame médico não ter sido hábil para fornecer informação precisa a respeito. Nesse relato, a evidência entomológica consistiu, principalmente, na presença de coleópteros e dípteros (Arnaldos et al., 2004).

Após o equilíbrio da temperatura corpórea com a do ambiente e o início do processo de putrefação, não é possível a aplicação de estimativa tradicional viável do IPM. Técnicas médicas, como mensuração da temperatura corpórea ou análise das alterações cadavéricas, tais como rigor ou livor mortis, só podem aferir o IPM com precisão nos primeiros dois ou três dias pósmorte. Porém, pelo cálculo da idade dos insetos imaturos que se alimentam do cadáver e pela análise das espécies necrófagas presentes, podese estimar o IPM no período de dias a meses (Amendt et al., 2007).

Na prática veterinária, os estudos direcionados à estimativa do IPM com aplicação da entomologia forense e finalidade jurídica são escassos, tornando-se necessário o desenvolvimento e a divulgação de estudos dessa natureza. Assim, objetivou-se com este trabalho estimar o intervalo pós-morte com base em evidências entomológicas em um canino.

\section{CASUÍSTICA}

Foi localizada uma carcaça de animal às margens da rodovia BR-230, nas proximidades do quilômetro sete, bairro de Intermares, na cidade de Cabedelo, Paraíba, Brasil (Fig. 1A). Essa área situa-se a $3 \mathrm{~m}$ acima do nível do mar, o clima é tropical chuvoso, com verão seco, e a precipitação média anual é de $1.634 .2 \mathrm{~mm}$ (Brasil, 2005).
Ao chegar ao local, às sete horas da manhã do dia 27 de setembro de 2011, constatou-se ser a carcaça de um cão doméstico, pelagem preta, idade adulta, sem raça definida, porte médio, em estado avançado de decomposição, na fase coliquativa da putrefação (Fig. 1B). Procedeu-se ao registro fotográfico da carcaça e coletaram-se amostras de larvas em todas as áreas corpóreas do animal. Essas foram acondicionadas em potes plásticos, contendo um pouco de terra do local, e conduzidas ao Laboratório de Entomologia da Universidade Federal da Paraíba.

No laboratório, as larvas foram criadas em temperatura média de $26,4^{\circ} \mathrm{C}$ e umidade média de $72,9 \%$ até eclodirem os primeiros dípteros adultos, identificados, de acordo com as chaves de identificação, como Chrysomya albiceps (Wiedemann, 1819) (Fig. 2), família Calliphoridae (Mello, 2003; Carvalho e MelloPatiu, 2008)

Passados seis dias entre o período de coleta e a eclosão dos adultos, 3,34 dias foi o intervalo mínimo entre a postura e o momento da coleta das larvas na carcaça. Assim, estimou-se que a noite do dia 23 de setembro de 2011 foi o provável momento da postura dos ovos, e o período transcorrido desde então (3,34 dias) estabelece o IPM mínimo do modelo animal.

\section{DISCUSSÃO}

A família Calliphoridae consiste de muscoides comumente conhecidos como varejeiras e tem distribuição em todo o mundo, sendo introduzida no Brasil a partir da década de 70 (Vargas e Wood, 2010). Estes constituem o tipo mais comum de inseto coletado durante investigações criminais, como observado no presente estudo, principalmente pela sua considerável habilidade de dispersão e adaptação e seu apetite voraz, sendo predadores de larvas de outras moscas.

Em diversos estudos em que se empregam carcaças de animais como iscas para obtenção de insetos, esta espécie geralmente é predominante entre os dípteros, principalmente pela sua abundância (Carvalho et al., 2004). 

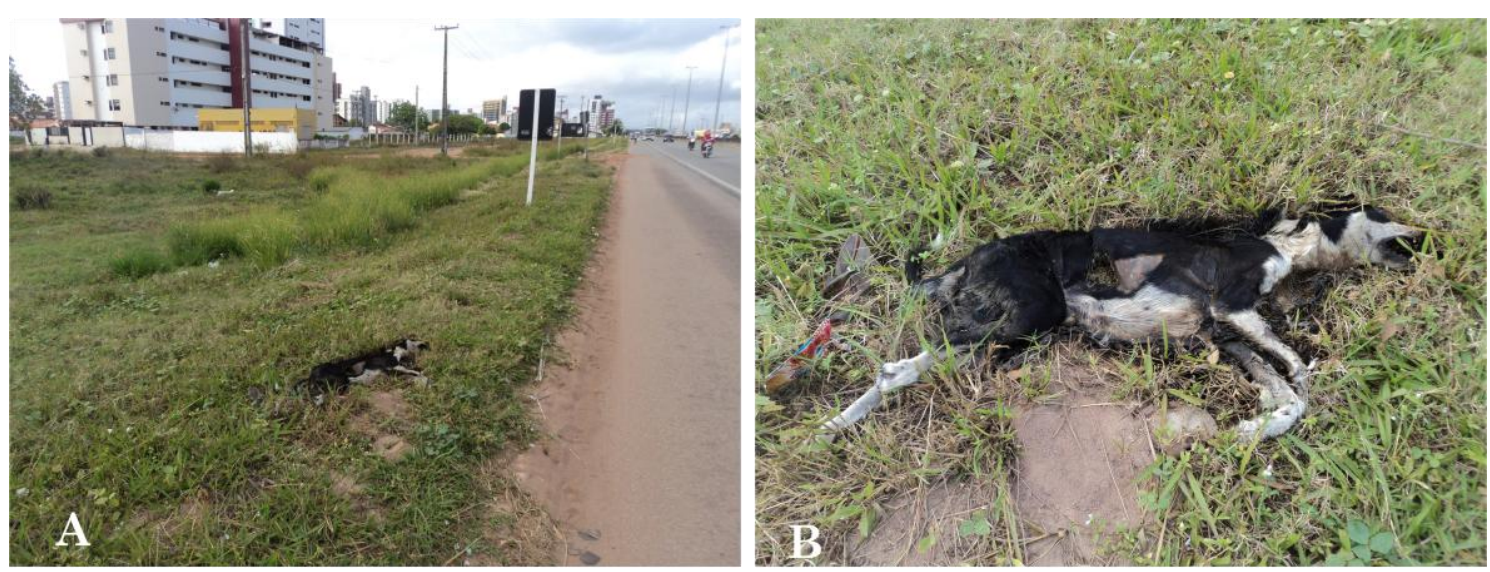

Figura 1. (A) Visão geral da área onde se localizou o cadáver de um canino. (B) Detalhe do animal encontrado em estágio avançado de decomposição. Cabedelo-PB. 2011.

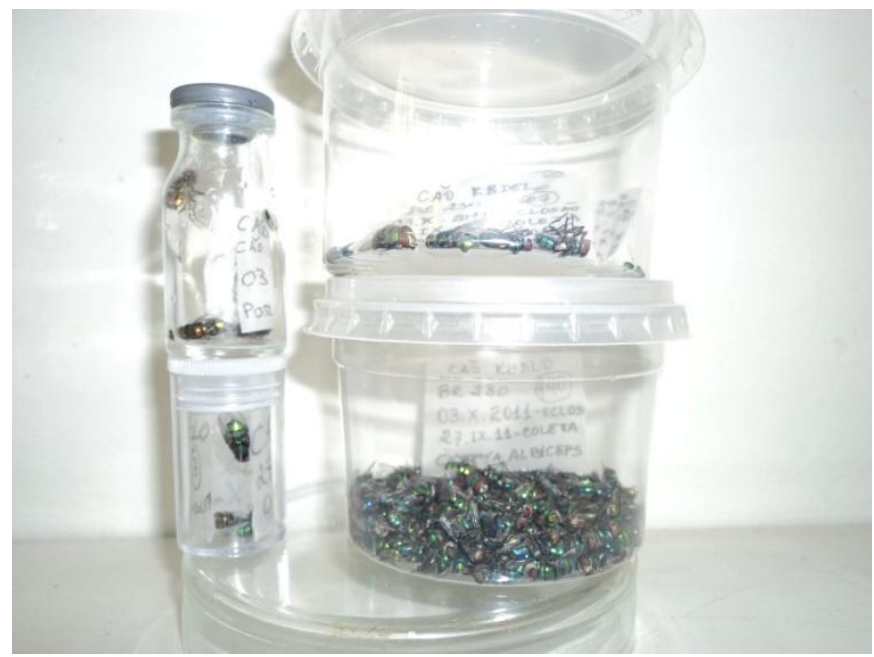

Figura 2. Dípteros adultos de Chrysomya albiceps.

Kosmann et al. (2011), no estado de Minas Gerais, indicaram a média de desenvolvimento de C. albiceps (do ovo ao adulto) em 264 horas (11 dias) e estimaram o IPM com base no período de atividade do inseto, em decorrência da falta de dados de temperatura do ar, do cadáver no local do crime, bem como da grande variação da temperatura e umidade no Cerrado e da distância da estação onde foram coletados os dados. No presente estudo, de acordo com a estação meteorológica local, foram obtidas temperatura média de $25,6^{\circ} \mathrm{C}$ e umidade relativa do ar (UR) de 74,68\% no local de coleta, dados esses que perduraram também nos seis dias anteriores à coleta.
As condições laboratoriais de temperatura e umidade empregadas para criação das larvas obtidas do canino foram semelhantes àquelas observadas nos seis dias anteriores à coleta no local. Sob essas condições, o grau dia acumulado (GDA) esperado para esta espécie se aproxima de 158,78 , e o tempo médio de desenvolvimento em dias de 9,34, segundo estudo de Queiroz (1996), que obteve esses dados criando larvas de C. albiceps à temperatura de $27^{\circ} \mathrm{C}$ e $70 \%$ UR em laboratório no Rio de Janeiro. Ressalta-se que o cálculo do GDA baseia-se em dados de desenvolvimento das espécies envolvidas, compreendendo desde a deposição dos ovos até a mosca adulta em temperatura similar ou próxima à obtida no local da morte. 


\section{CONCLUSÕES}

Com base nos resultados obtidos, conclui-se que a entomologia forense, como ferramenta para estimativa do intervalo pós-morte, mostrou-se eficaz e determinante na elucidação do caso em questão. Desta forma, espera-se que, futuramente, essa área desempenhe um importante papel no esclarecimento de óbitos, subsidiando a medicina veterinária legal, e que parcerias entre instituições de ensino e polícia científica sejam firmadas no intuito de contribuir com o desenvolvimento científico da entomologia forense no Brasil.

\section{AGRADECIMENTOS}

Ao Departamento de Sistemática e Ecologia da Universidade Federal da Paraíba, pela permissão de uso das instalações e infraestrutura do Laboratório de Entomologia.

\section{REFERÊNCIAS}

AMENDT, J.; CAMPOBASSO, C.P.; GAUDRY, E. et al. Best practice in forensic entomology standards and guidelines. Int. J. Legal Med., v.121, p.90-104, 2007.

ARNALDOS, M.I.; SÁNCHEZ, F.; ÁLVAREZ, P.; GARCÍA, M.D. A forensic entomology case from the Southeastern Iberian Peninsula. Aggrawal's Internet J. Forensic Med. Toxicol., v.5, p.22-25, 2004.

BRASIL. Ministério de Minas e Energia. CPRM - Serviço Geológico do Brasil. Diagnóstico do município de Cabedelo, estado da Paraíba. Projeto cadastro de fontes de abastecimento por água subterrânea. Recife: CPRM/PRODEEM, 2005. 20p.

CARVALHO, L.M.L.; THYSSEN, P.J.; GOFF, M.L.; LINHARES, A.X. Observations on the succession patterns of necrophagous insects onto a pig carcass in an urban area of Southeastern Brazil. Aggrawal's Internet J. Forensic Med. Toxicol., v.5, p.33-39, 2004.
CARVALHO, C.J.B.; MELLO-PATIU, C.A. Key to the adults of the most common forensic species of Diptera in South America. Rev. Bras. Entomol., v.52, p.390-406, 2008.

CATTS, E.P.; GOFF, M.L. Forensic entomology in criminal investigations. Annu. Rev. Entomol., v.37, p.253-272, 1992.

FISHER, P.; WALL, R.; ASHWORTH, J.R. Attraction of the sheep blowfly, Lucilia sericata (Diptera: Calliphoridae) to carrion bait in the field. Bull. Entomol. Res., v.88, p.611-616, 1998.

KOSMANN, C.; MACEDO, M.P.; BARBOSA, T.A.F.; PUJOL-LUZ, J.R. Chrysomya albiceps (Wiedemann) and Hemilucilia segmentaria (Fabricius) (Diptera, Calliphoridae) used to estimate the postmortem interval in a forensic case in Minas Gerais, Brazil. Rev. Bras. Entomol., v.55, p.621-623, 2011.

MELLO, R.P. Chave para identificação das formas adultas das espécies da família Calliphoridae (Diptera, Brachycera, Ciclorrhapha) encontradas no Brasil. Entomol. Vectores, v.10, p.255-268, 2003.

QUEIROZ, M.M.C. Temperature Requirements of Chrysomya albiceps (Wiedemann, 1819) (Diptera, Calliphoridae) under Laboratory Conditions. Mem. Inst. Oswaldo Cruz, v.91, p.785-788, 1996.

SMITH, K.G.V. A manual of forensic entomology. Ithaca, NY, USA: Cornell University Press, 1986. 205p.

VARGAS, J.; WOOD, D.M. Calliphoridae. In: BROWN, B.V.; BORKENT, A.; CUMMING, J.M. et al. (Eds.). Manual of Central American Diptera. Vol. 2. Ottawa: NCR Research Press, 2010. p.1297-1304. 